OPEN ACCESS

Edited by:

Arcady A. Putilov,

Federal Research Center of

Fundamental and Translational

Medicine, Russia

Reviewed by:

Mikhail Bochkarev,

Almazov National Medical Research

Centre, Russia

Shyam Odeti,

Carilion Clinic, United States

*Correspondence:

Yingjie Su

doctorsuyingjie@sina.com orcid.org/0000-0001-6566-8755

Liudang $\mathrm{He}$

923374687@qq.com

Ning Ding

doctordingning@sina.com

doctordingning@csu.edu.cn orcid.org/0000-0001-7805-2191

Specialty section

This article was submitted to Family Medicine and Primary Care,

a section of the journal

Frontiers in Medicine

Received: 01 July 2021 Accepted: 09 November 2021 Published: 24 December 2021

Citation:

Su Y, Li C, Long Y, He L and Ding N (2021) Association Between Bedtime at Night and Systolic Blood Pressure

in Adults in NHANES.

Front. Med. 8:734791.

doi: 10.3389/fmed.2021.734791

\section{Association Between Bedtime at Night and Systolic Blood Pressure in Adults in NHANES}

\author{
Yingjie Su*, Changluo Li, Yong Long, Liudang He* and Ning Ding * \\ Department of Emergency Medicine, The Affiliated Changsha Central Hospital, Hengyang Medical School, University of \\ South China, Changsha, China
}

Objectives: This study aimed to explore the association between bedtime at night and systolic blood pressure (SBP) in adults.

Methods: We conducted a cross-sectional study composed of 7,642 individuals from the National Health and Nutrition Examination Survey (NHANES). Bedtime was defined as the response to the question: "What time do you usually fall asleep on weekdays or workdays?" SBP was taken using the average of all measured values. Multiple linear regression analyses were done to explore the relationship between bedtime and SBP.

Results: The bedtime was changed from categorical variable to continuous variable for data analysis, and a significantly negative association was identified between bedtime and $\operatorname{SBP}(\beta,-0.23[95 \% \mathrm{Cl},-0.43,-0.02])$. With the delay of bedtime, the SBP showed a gradual decrease trend, and it was dropped to the lowest at 0:00. After 0:00, the SBP was gradually increased with the delay of sleep time. The stratified analyses showed that in the female group, with the delay of bedtime, the range of SBP was decreased more obviously at 0:00. In the 18-45 year group, bedtime had little effect on SBP. Among $\geq 45$ years old group, this trend was still the same. In the black group, an obvious downward trend was found at 22:00.

Conclusion: With the delay of bedtime, the SBP had shown a gradual decrease trend, and it was dropped to the lowest at 0:00. After 0:00, the SBP was gradually increased with the delay of sleep time. Bedtime and SBP showed a U-shaped relationship.

Keywords: bedtime, systolic blood pressure, hypertension, gender, NHANES

\section{INTRODUCTION}

Hypertension has been a global health problem, which is caused by a combination of genetic and environmental factors (1). In the United States, nearly one-third of adults have suffered from hypertension (2). In recent years, the prevention and treatment of hypertension through lifestyle changes have evoked the awareness of people. Sleep has been identified as a key lifestyle risk factor for cardiovascular disease (3). Sleep can be evaluated from multiple perspectives, including duration, quality, regularity, time, and the existence of sleep disorders. Since sleep duration is the simplest and most direct measure of sleep, it has been utilized as a goal to explore the relationship between sleep and health (4). Related research studies have clarified that the proportion of American adults who sleep less than 7-8 h a day had increased from $20-23 \%$ in 1985 to nearly 


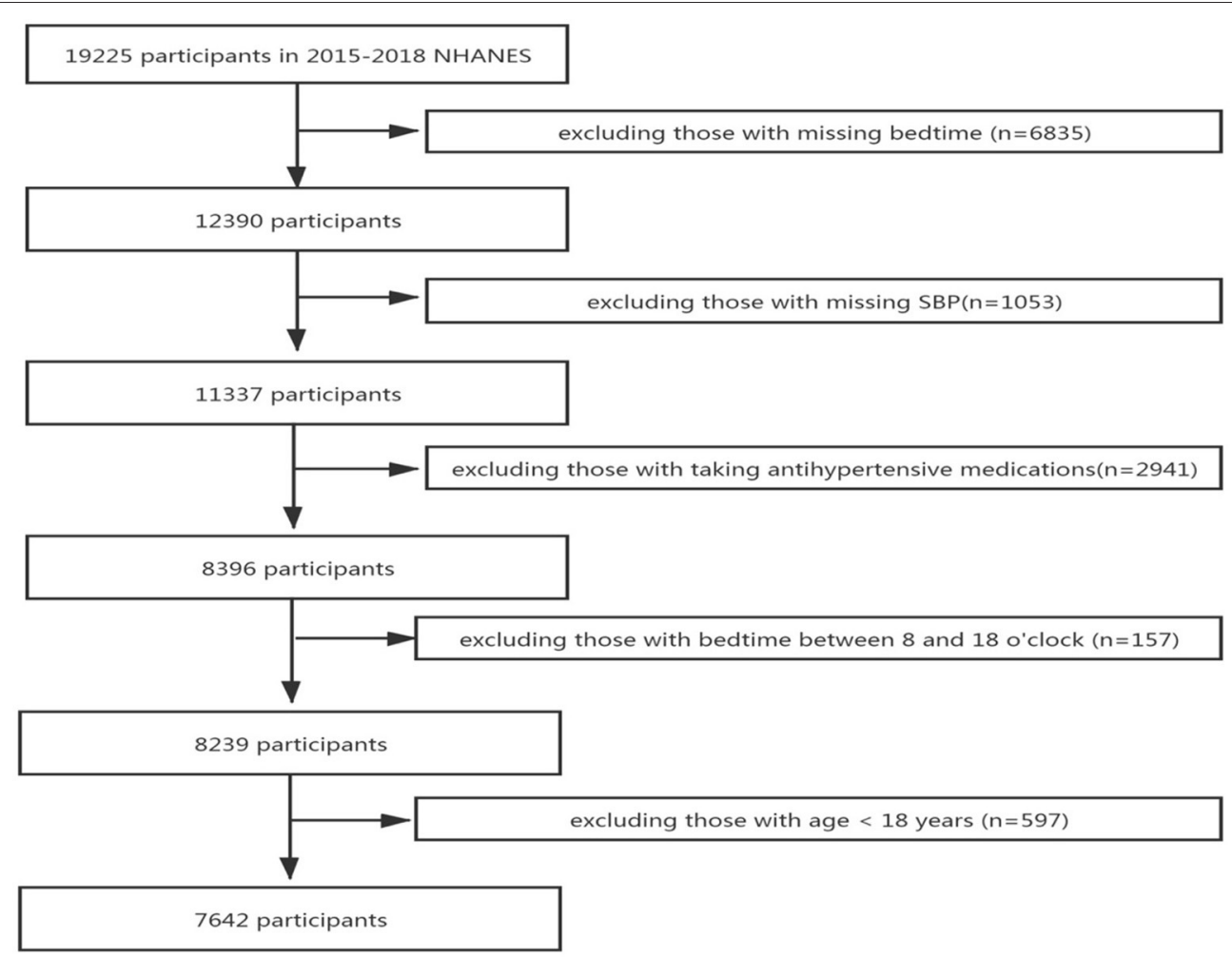

FIGURE 1 | Flowchart of the study design and participants excluded from the study.

$30 \%$ in 2005-2007 $(5,6)$. Many studies also have shown that blood pressure (BP) was affected by sleep duration (7-11).

The $24 \mathrm{~h}$ sleep-wake cycle was closely related to BP and was also affected by several endogenous circadian rhythms and circulatory exogenous factors, which was a coordinated process involving rhythmic changes in sensory, motor, autonomy, endocrine, and brain processes. This change had a certain impact on cardiovascular function and BP (12). Moreover, there were obvious circadian rhythms in BP fluctuations, which were increased during the day and decreased in the middle of the night. Falling asleep too early or too late could disrupt this pattern, and the lack of this normal decline pattern was believed to be a better predictor of cardiometabolic disease risk and mortality $(13,14)$.

However, few studies have explored the effect of bedtime on $\mathrm{BP}$. Hence, this study aimed to explore the relationship between bedtime at night and systolic BP (SBP).

\section{METHODS}

\section{Study Population}

We retrieved two cycles of data from 2015 to 2018 in the National Health and Nutrition Examination Survey (NHANES)

Abbreviations: UA, uric acid; SBP, systolic blood pressure; BP, blood pressure; BMI, body mass index; HDL, high-density lipoprotein; TC, total cholesterol; LDL, low-density lipoprotein; CI, confidence interval; OR, odds ratio; TPA, total physical activity; GFR, glomerular filtration rate. database for research. A total of 19,225 potential participants were included in the study, and 11,583 participant were excluded for the following reasons: missing bedtime $(n=6,835)$, missing SBP data $(n=1,053)$, taking antihypertensive medications ( $n=2,941)$, bedtime between 8:00 and 18:00 o'clock $(n=157)$, and age less than 18 years $(n=597)$. Finally, 7,642 participants were included in the study, after all exclusion criteria were met (Figure 1).

\section{Definition}

Bedtime was defined as the response to the question: "What time do you usually fall asleep on weekdays or workdays?", the responses were categorized into 13 groups:19:00, 20:00, 21:00, 22:00, 23:00, 0:00, 1:00, 2:00, 3:00, 4:00, 5:00, 6:00, and 7:00. Moreover, it was changed into a continuous variable for data analysis.

Well-trained and certified inspectors used standardized protocols and calibrated equipment to obtain $\mathrm{BP}$ readings. Three consecutive BP readings were obtained through auscultation. If the BP measurement was not completed successfully, the fourth measurement would be performed. The SBP was the average of all available measurement data.

\section{Covariates}

In our research, sociodemographic, lifestyle, metabolic, and sleep factors were collected. Sociodemographic factors included race, age, and gender. The race was classified into 4 groups: 
TABLE 1 | Description of 7,642 participants included in the present study.

\begin{tabular}{|c|c|c|c|c|}
\hline & Total $(n=7,642)$ & Male $(n=3,717)$ & Female $(n=3,925)$ & $P$-value \\
\hline \multicolumn{5}{|c|}{ Sociodemographic factors } \\
\hline Age (years) & & & & $<0.001$ \\
\hline $18-44$ & 4,242 (55.51\%) & 1,993 (53.62\%) & 2,249 (57.30\%) & \\
\hline $45-59$ & 1,737 (22.73\%) & $830(22.33 \%)$ & $907(23.11 \%)$ & \\
\hline$\geq 60$ & 1,663 (21.76\%) & $894(24.05 \%)$ & 769 (19.59\%) & \\
\hline Race & & & & 0.222 \\
\hline Mexican american & 1,332 (17.43\%) & $636(17.11 \%)$ & $696(17.73 \%)$ & \\
\hline White & $2,516(32.92 \%)$ & $1,266(34.06 \%)$ & $1,250(31.85 \%)$ & \\
\hline Black & $1,478(19.34 \%)$ & $713(19.18 \%)$ & 765 (19.49\%) & \\
\hline Other race & $2,316(30.31 \%)$ & 1,102 (29.65\%) & $1,214(30.93 \%)$ & \\
\hline \multicolumn{5}{|l|}{ Lifestyle factors } \\
\hline Alcohol consumption & & & & $<0.001$ \\
\hline No drinking & 1,039 (13.60\%) & $544(14.64 \%)$ & 495 (12.61\%) & \\
\hline Drinking & $4,981(65.18 \%)$ & $2,579(69.38 \%)$ & 2,402 (61.20\%) & \\
\hline Not recorded & 1,622 (21.22\%) & 594 (15.98\%) & 1,028 (26.19\%) & \\
\hline Smoke & & & & $<0.001$ \\
\hline Smoking & $1,422(18.61 \%)$ & 859 (23.11\%) & $563(14.34 \%)$ & \\
\hline No smoking & 1,465 (19.17\%) & $914(24.59 \%)$ & $551(14.04 \%)$ & \\
\hline Not recorded & $4,755(62.22 \%)$ & $1,944(52.30 \%)$ & $2,811(71.62 \%)$ & \\
\hline TPA (minutes) & & & & $<0.001$ \\
\hline$<150$ & $1,212(15.86 \%)$ & 465 (12.51\%) & 747 (19.03\%) & \\
\hline$\geq 150,<300$ & 340 (4.45\%) & 135 (3.63\%) & 205 (5.22\%) & \\
\hline$\geq 300,<450$ & 289 (3.78\%) & 134 (3.61\%) & 155 (3.95\%) & \\
\hline$\geq 450$ & 1,779 (23.28\%) & 1,015 (27.31\%) & 764 (19.46\%) & \\
\hline Not recorded & 4,022 (52.63\%) & $1,968(52.95 \%)$ & $2,054(52.33 \%)$ & \\
\hline \multicolumn{5}{|l|}{ Metabolic factors } \\
\hline GFR $\left(\mathrm{ml} / \mathrm{min} / 1.73 \mathrm{~m}^{2}\right)$ & $100.35 \pm 27.49$ & $97.29 \pm 25.07$ & $103.24 \pm 29.31$ & $<0.001$ \\
\hline UA (umol/L) & $313.49 \pm 82.47$ & $356.13 \pm 75.89$ & $273.19 \pm 66.67$ & $<0.001$ \\
\hline $\mathrm{TC}(\mathrm{mmol} / \mathrm{L})$ & $4.90 \pm 1.06$ & $4.88 \pm 1.08$ & $4.92 \pm 1.04$ & 0.080 \\
\hline LDL (mmol/L) & $2.91 \pm 0.90$ & $2.95 \pm 0.91$ & $2.88 \pm 0.90$ & 0.013 \\
\hline $\mathrm{HDL}$ (mmol/L) & $1.40 \pm 0.42$ & $1.26 \pm 0.37$ & $1.52 \pm 0.43$ & $<0.001$ \\
\hline $\mathrm{SBP}(\mathrm{mmHg})$ & $121.59 \pm 17.21$ & $124.14 \pm 16.32$ & $119.18 \pm 17.68$ & $<0.001$ \\
\hline $\mathrm{BMl}\left(\mathrm{kg} / \mathrm{m}^{2}\right)$ & & & & $<0.001$ \\
\hline$<18.5$ & 162 (2.12\%) & $64(1.72 \%)$ & 98 (2.50\%) & \\
\hline $18.5-24.9$ & 2,316 (30.31\%) & 1,091 (29.35\%) & 1,225 (31.21\%) & \\
\hline 25-29.9 & 2,375 (31.08\%) & 1,309 (35.22\%) & 1,066 (27.16\%) & \\
\hline$\geq 30$ & 2,714 (35.51\%) & 1,210 (32.55\%) & 1,504 (38.32\%) & \\
\hline Not recorded & 75 (0.98\%) & 43 (1.16\%) & $32(0.82 \%)$ & \\
\hline Diabetes & & & & 0.026 \\
\hline Yes/Borderline & 751 (9.83\%) & 395 (10.63\%) & 356 (9.07\%) & \\
\hline No & $6,886(90.11 \%)$ & 3,321 (89.35\%) & 3,565 (90.83\%) & \\
\hline Not recorded & $5(0.07 \%)$ & $1(0.03 \%)$ & $4(0.10 \%)$ & \\
\hline
\end{tabular}

GFR, glomerular filtration rate; UA, uric acid; SBP, systolic blood pressure; BMI, body mass index; HDL, high-density lipoprotein; TC, total cholesterol; LDL, low-density lipoprotein; TPA, total physical activity. Mean +/- SD for: GFR, UA, SBP, TC, LDL, HDL. P-value was calculated by linear regression model. \% for: race, alcohol consumption, smoke, age, BMI, diabetes, TPA. P-value was calculated by chi-square test.

Mexican American, White, Black, and other race. Age was classified into 3 groups: young (18-44), middle-aged (45-59), and old $(\geq 60)$. Lifestyle factors included alcohol consumption, smoke, and total physical activity (TPA). Alcohol consumption was defined as the response to the question: "In the past
12 months, how often did you drink any type of alcoholic beverage?", and the responses were divided into 3 groups: drinking, no drinking, and not recorded. Smoking was defined as the response to the question: "Do you now smoke cigarettes?", and the responses were divided into 3 groups: smoking, no 
TABLE 2 | Sleep factors description of 7,642 participants included in the present study.

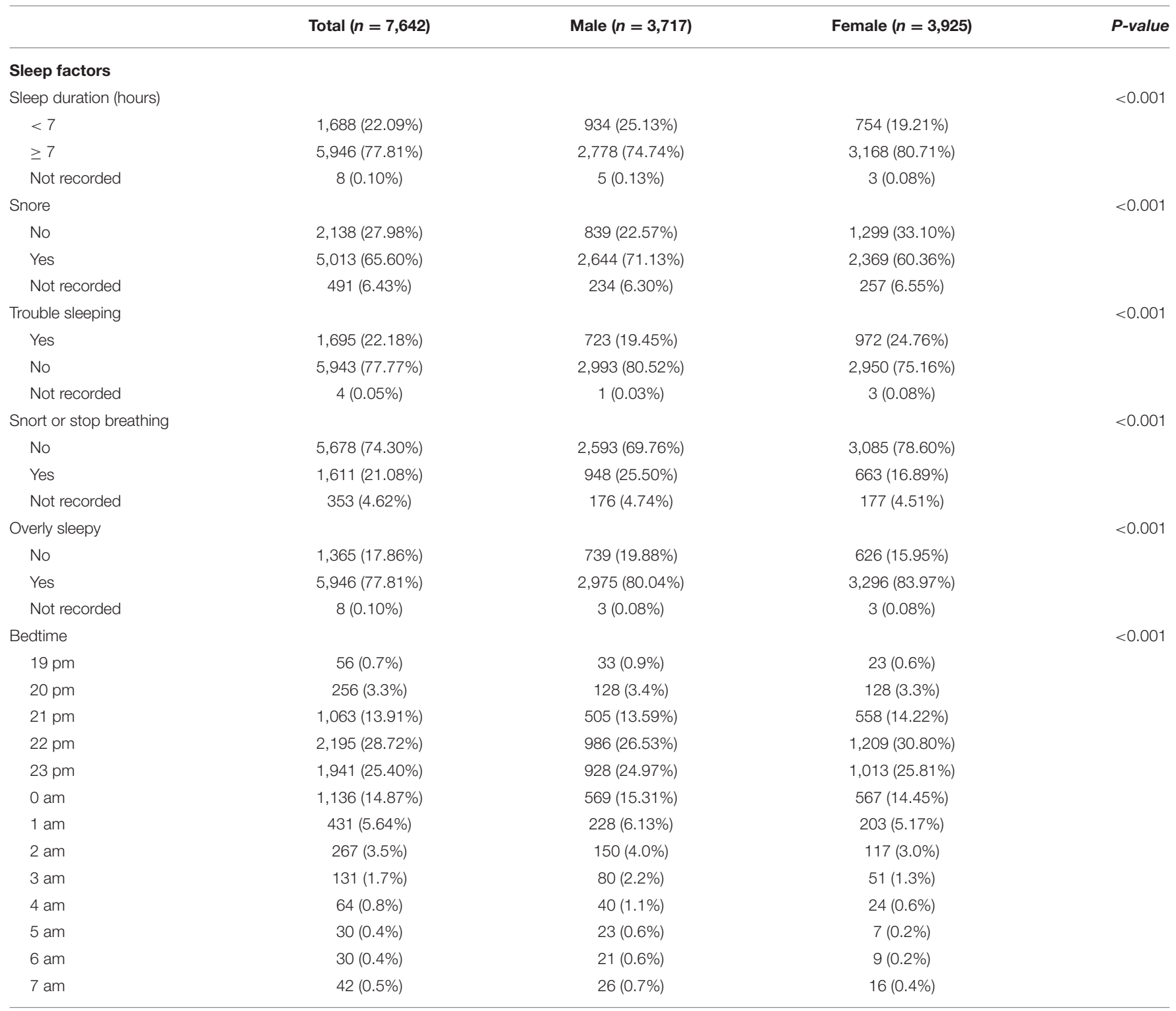

$\%$ for: sleep duration, snore, trouble sleeping, snort or stop breathing, overly sleepy, bedtime. P-value was calculated by chi-square test.

smoking, and not recorded. According to the physical activity guideline and previous literature $(15,16)$, the TPA was divided into 5 groups: $<150,150-300,300-450, \geq 450 \mathrm{~min}$, and not recorded. Metabolic factors included glomerular filtration rate (GFR), urea acid (UA), total cholesterol (TC), low-density lipoprotein (LDL), high-density lipoprotein (HDL), body mass index (BMI), and diabetes. GFR was estimated by the simplified Modification of Diet in Renal Disease (MDRD) equation: 186 $\times \mathrm{SC}^{-1.154} \times \mathrm{Age}^{-0.203} \times$ (0.742 if female) (17). According to the WHO guidelines, BMI was divided into underweight $\left(<18.5 \mathrm{~kg} / \mathrm{m}^{2}\right)$, normal weight $\left(18.5-24.99 \mathrm{~kg} / \mathrm{m}^{2}\right)$, overweight $\left(25-29.99 \mathrm{~kg} / \mathrm{m}^{2}\right)$, and obesity $\left(\geq 30 \mathrm{~kg} / \mathrm{m}^{2}\right)(18)$. Diabetes was defined as the responses to the question: "Have you ever been told by a doctor or health professional that you have diabetes or sugar diabetes?", and the responses were divided into 4 groups: yes, no, borderline, and not recorded. The method of obtaining other covariates, including UA, TC, LDL, HDL, can be found at www.cdc.gov/nchs/nhanes/.

\section{Sleep Factors}

Sleep duration was defined as the responses to the question: "How much sleep do you usually get at night on weekdays or workdays?", and based on the guideline (19), the responses were categorized into 3 groups: $<7 \mathrm{~h}, \geq 7 \mathrm{~h}$, and not recorded. Snore was based on the responses to the question: "In the past 12 months, how often did you snore while you were sleeping?" Trouble sleeping was based on the responses: "Have you ever told a doctor or other health professional that you have trouble sleeping?" Snort or stop breathing was based on the responses to the question: "in the past 12 months, how often did you snort, 
TABLE 3 | Univariate analysis for systolic blood pressure.

\begin{tabular}{|c|c|c|}
\hline & Statistics & $\beta,(95 \% \mathrm{Cl}), \mathrm{P}$ \\
\hline \multicolumn{3}{|l|}{ Gender } \\
\hline Male & $3,717(48.64 \%)$ & Ref \\
\hline Female & 3,925 (51.36\%) & $-4.96(-5.73,-4.20)<0.0001$ \\
\hline \multicolumn{3}{|l|}{ Race } \\
\hline White & $2,516(32.92 \%)$ & Ref \\
\hline Mexican american & $1,332(17.43 \%)$ & $-0.61(-1.75,0.53) 0.2927$ \\
\hline Black & $1,478(19.34 \%)$ & $3.79(2.69,4.89)<0.0001$ \\
\hline Other race & $2,316(30.31 \%)$ & $-1.55(-2.51,-0.58) 0.0017$ \\
\hline \multicolumn{3}{|l|}{ Age (years) } \\
\hline $18-44$ & $4,242(55.51 \%)$ & Ref \\
\hline $45-59$ & $1,737(22.73 \%)$ & $9.39(8.52,10.27)<0.0001$ \\
\hline$\geq 60$ & $1,663(21.76 \%)$ & $17.30(16.41,18.19)<0.0001$ \\
\hline \multicolumn{3}{|l|}{ Alcohol consumption } \\
\hline No drinking & 1,039 (13.60\%) & Ref \\
\hline Drinking & $4,981(65.18 \%)$ & $-4.62(-5.77,-3.47)<0.0001$ \\
\hline Not recorded & $1,622(21.22 \%)$ & $-5.08(-6.41,-3.75)<0.0001$ \\
\hline \multicolumn{3}{|l|}{ TPA (minutes) } \\
\hline$<150$ & $1,212(15.86 \%)$ & Ref \\
\hline$\geq 150,<300$ & $340(4.45 \%)$ & $-2.00(-4.07,0.06) 0.0572$ \\
\hline$\geq 300,<450$ & $289(3.78 \%)$ & $-2.97(-5.17,-0.77) 0.0082$ \\
\hline$\geq 450$ & $1,779(23.28 \%)$ & $-4.43(-5.68,-3.18)<0.0001$ \\
\hline Not recorded & $4,022(52.63 \%)$ & $-3.51(-4.61,-2.40)<0.0001$ \\
\hline \multicolumn{3}{|l|}{ Smoke } \\
\hline Smoking & $1,422(18.61 \%)$ & Ref \\
\hline No smoking & 1,465 (19.17\%) & $2.62(1.38,3.87)<0.0001$ \\
\hline Not recorded & $4,755(62.22 \%)$ & $-3.05(-4.06,-2.04)<0.0001$ \\
\hline \multicolumn{3}{|l|}{$\mathrm{BMI}\left(\mathrm{kg} / \mathrm{m}^{2}\right)$} \\
\hline $18.5-24.9$ & $2,316(30.31 \%)$ & Ref \\
\hline$<18.5$ & $162(2.12 \%)$ & $-3.84(-6.54,-1.14) 0.0053$ \\
\hline $25-29.9$ & $2,375(31.08 \%)$ & $3.72(2.75,4.69)<0.0001$ \\
\hline$\geq 30$ & $2,714(35.51 \%)$ & $6.58(5.64,7.52)<0.0001$ \\
\hline Not recorded & $75(0.98 \%)$ & $11.92(8.02,15.81)<0.0001$ \\
\hline \multicolumn{3}{|l|}{ Diabetes } \\
\hline No & $6,886(90.11 \%)$ & Ref \\
\hline Yes/Borderline & 751 (9.83\%) & $6.80(5.51,8.09)<0.0001$ \\
\hline Not recorded & $5(0.07 \%)$ & $-14.80(-29.78,0.18) 0.0529$ \\
\hline $\operatorname{GFR}\left(\mathrm{ml} / \mathrm{min} / 1.73 \mathrm{~m}^{2}\right)$ & $100.35 \pm 27.49$ & $-0.13(-0.15,-0.12)<0.0001$ \\
\hline UA (umol/L) & $313.49 \pm 82.47$ & $0.04(0.04,0.04)<0.0001$ \\
\hline TC (mmol/L) & $4.90 \pm 1.06$ & $2.87(2.51,3.24)<0.0001$ \\
\hline LDL (mmol/L) & $2.91 \pm 0.90$ & $3.08(2.43,3.73)<0.0001$ \\
\hline $\mathrm{HDL}$ (mmol/L) & $1.40 \pm 0.42$ & $-0.94(-1.87,-0.01) 0.0478$ \\
\hline \multicolumn{3}{|l|}{ Sleep duration (hours) } \\
\hline$<7$ & $1,688(22.09 \%)$ & Ref \\
\hline$\geq 7$ & $5,946(77.81 \%)$ & $-2.22(-3.15,-1.29)<0.0001$ \\
\hline Not recorded & $8(0.10 \%)$ & $-1.74(-13.67,10.20) 0.7756$ \\
\hline \multicolumn{3}{|l|}{ Snore } \\
\hline No & $2,138(27.98 \%)$ & Ref \\
\hline Yes & $5,013(65.60 \%)$ & $4.38(3.52,5.25)<0.0001$ \\
\hline Not recorded & $491(6.43 \%)$ & $6.24(4.56,7.91)<0.0001$ \\
\hline
\end{tabular}

(Continued)
TABLE 3 | Continued

\begin{tabular}{|c|c|c|}
\hline & Statistics & $\beta,(95 \% \mathrm{Cl}), \mathrm{P}$ \\
\hline \multicolumn{3}{|l|}{ Trouble sleeping } \\
\hline Yes & 1,695 (22.18\%) & Ref \\
\hline No & $5,943(77.77 \%)$ & $-0.86(-1.79,0.07) 0.0707$ \\
\hline Not recorded & $4(0.05 \%)$ & $0.08(-16.81,16.96) 0.9930$ \\
\hline \multicolumn{3}{|c|}{ Snort or stop breathing } \\
\hline No & $5,678(74.30 \%)$ & Ref \\
\hline Yes & $1,611(21.08 \%)$ & $3.06(2.11,4.00)<0.0001$ \\
\hline Not recorded & $353(4.62 \%)$ & $4.38(2.54,6.23)<0.0001$ \\
\hline \multicolumn{3}{|l|}{ Overly sleepy } \\
\hline No & $1,365(17.86 \%)$ & Ref \\
\hline Yes & $5,946(77.81 \%)$ & $-2.44(-3.45,-1.43)<0.0001$ \\
\hline Not recorded & $8(0.10 \%)$ & $13.19(-0.58,26.97) 0.0606$ \\
\hline Bedtime & $4.88 \pm 1.76$ & $-0.56(-0.78,-0.34)<0.0001$ \\
\hline
\end{tabular}

Ref, reference; TPA, total physical activity; BMI, body mass index; GFR, glomerular filtration rate; UA, uric acid; HDL, high-density lipoprotein; TC, total cholesterol; LDL, low-density lipoprotein.

gasp, or stop breathing while you were asleep?" Overly sleepy was defined as the responses to the question: "In the past month, how often did you feel excessively or overly sleepy during the day?" The above 4 variables, namely, snore, trouble sleeping, snort or stop breathing, and overly sleepy, were divided into 3 groups according to the answers: yes, no, and not recorded.

\section{Statistical Analysis}

A multivariate linear regression model was used to assess the correlation between bedtime at night and SBP in adults. The covariates mentioned above were adjusted as potential confounders. The continuous variables were represented by mean \pm SD (normal distribution) or median (quartile) (skew distribution), which included GFR, UA, TC, LDL, $\mathrm{HDL}$, and SBP. Categorical variables were represented by percentage or frequency, which included age, race, alcohol consumption, smoke, TPA, BMI, diabetes, sleep duration, snore, trouble sleeping, snort or stop breathing, overly sleepy, and bedtime. To calculate the differences between male and female, a linear regression model was used for continuous variables or chi-square tests for categorical variables. The values of missing continuous covariates were indicated by dummy variables, including GFR, UA, TC, LDL, HDL, and the missing ratios were 6.4, 6.4, 6.2, 57.4, and 6.2\%, respectively. The missing categorical variables were included in the analysis as a single group, including alcohol consumption, smoking, TPA, BMI, diabetes, sleep duration, snore, trouble sleeping, snort or stop breathing, and being overly sleepy. We changed the bedtime from categorical variable to continuous variable for data analysis. Stratified analysis and smooth curve fittings were conducted to explore the relationship between bedtime and SBP based on gender, age, race, and BMI. The statistical software packages R (http://www.R-project.org) and EmpowerStats (http://www.empowerstats.com) were used for the 
TABLE 4 | Relationship between bedtime at night and SBP in different models.

\begin{tabular}{lccc}
\hline Exposure & Model I $(\boldsymbol{\beta}, \mathbf{9 5} \% \mathbf{C l}, \mathbf{P})$ & Model II $(\boldsymbol{\beta}, \mathbf{9 5} \% \mathbf{C l}, \mathbf{P})$ & Model III $(\boldsymbol{\beta}, \mathbf{9 5} \% \mathbf{C l}, \mathbf{P})$ \\
\hline $\begin{array}{l}\text { Bedtime } \\
4.88 \pm 1.76\end{array}$ & $-0.74(-0.97,-0.51)<0.0001$ & $-0.26(-0.47,-0.05) 0.0155$ & $-0.23(-0.43,-0.02) 0.0292$
\end{tabular}

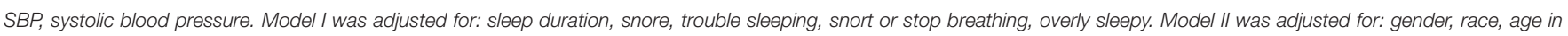
addition to model I. Model III was adjusted for: alcohol consumption, smoke, TPA, GFR, UA, TC, LDL, HDL, BMI, diabetes in addition to model II.

data analyses. When the $P$-value was $<0.05$, it was considered statistically significant.

\section{RESULTS}

\section{Participants Characteristics}

Table 1 shows the description of sociodemographic and baseline characteristics. Our study included 7,642 participants subclassified based on gender. Among the participants, the proportion of male and female was $48.64 \%(n=3,717)$ and $51.36 \%(n=3,925)$, respectively. In ethnicity, the proportion of Mexican American, White, and Black was $17.43,32.92$, and $19.34 \%$, respectively. Overall, the mean (SD) values for GFR, UA, TC, LDL, HDL, and SBP were $100.35(27.49) \mathrm{ml} / \mathrm{min} / 1.73 \mathrm{~m}^{2}, 313.49(82.47) \mu \mathrm{mol} / \mathrm{L}, 4.90$ (1.06) $\mathrm{mmol} / \mathrm{L}, 2.91(0.90) \mathrm{mmol} / \mathrm{L}, 1.40$ (0.42) $\mathrm{mmol} / \mathrm{L}$, and 121.59 (17.21) $\mathrm{mmHg}$, respectively. In the participants, $65.18 \%$ were alcohol drinkers, $18.61 \%$ were smokers, $55.51 \%$ were young, $30.31 \%$ were normal weight, and $9.83 \%$ were diabetes (yes/borderline). Table 2 shows the description of sleep factors. $22.09 \%$ of participants were sleep duration with $<7 \mathrm{~h}$, $65.60 \%$ were snored, $22.18 \%$ have trouble sleeping, $21.08 \%$ have snorted or stopped breathing, and $77.81 \%$ were overly sleepy. Table 3 shows the results of the univariate analysis of SBP.

\section{Association Between Bedtime at Night and SBP}

The results from multiple linear regression analyses are illuminated in Table 4, which are used to explore the association between bedtime and SBP. In model I, after adjustment for sleep factors: sleep duration, snore, trouble sleeping, snort or stop breathing, and overly sleepy, a significantly negative association was identified $(\beta,-0.74[95 \% \mathrm{CI},-0.97,-0.51])$. In model II, we adjusted for gender, race, and age in addition to the model I, a significantly negative association still presented $(\beta$, -0.26 [95\% CI, $-0.47,-0.05]$ ). In model III, we adjusted for alcohol consumption, smoke, TPA, GFR, UA, TC, LDL, HDL, BMI, and diabetes in addition to model II, a significantly negative association still existed $(\beta,-0.23$ [95\% CI, -0.43 , $-0.02])$. We also conducted a smooth curve fitting to explore the non-linear relationship between bedtime and SBP (Figure 2). With the delay of bedtime, the SBP had a gradual decrease trend, which was decreased to the minimum at 0:00, and then increased gradually.

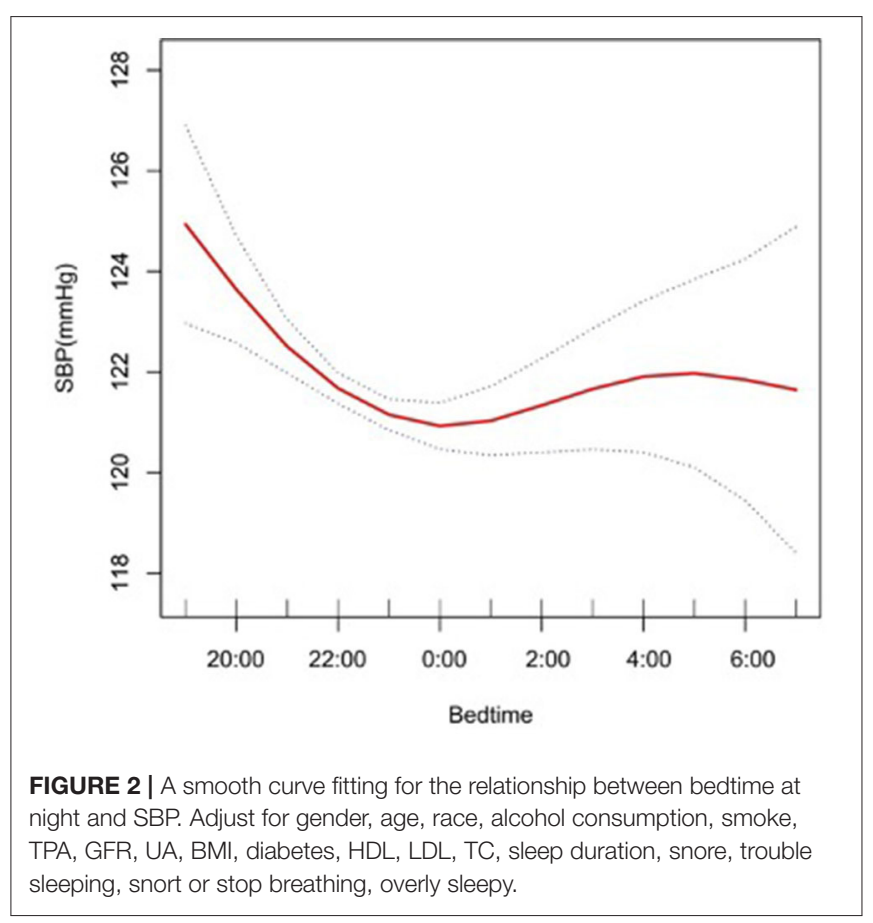

\section{Subgroup Analyses of Factors Influencing the Association Between Bedtime at Night and SBP}

In the subgroup analysis stratified by gender, race, age, and BMI, the association between bedtime and SBP is explored in Figures 2-6. All the potential confounding factors except the subgroup variable were adjusted. In the female group (Figure 3 ), with the delay of bedtime, the range of SBP was decreased more obviously at 0:00, then was increased gradually, and fell again after 4:00. For the second downward trend, we thought that the sample size at each time point was too small to reflect the true relationship. In different age groups (Figure 4), with the age increasing, BP was gradually increased. In the 18-44 year group, bedtime had little effect on SBP. Among the $\geq 45$ years old group, this trend also existed. In the Black group (Figure 5), an obvious downward trend was found at 22:00, and the SBP was the lowest. However, the trend was not found in Mexican Americans. In different BMI groups (Figure 6), the downward trend of SBP was more obvious in groups with 18.5-24.9 BMI. In the group with $\mathrm{BMI} \leq 18.5$, the sample size was too small to reflect the true relationship. 


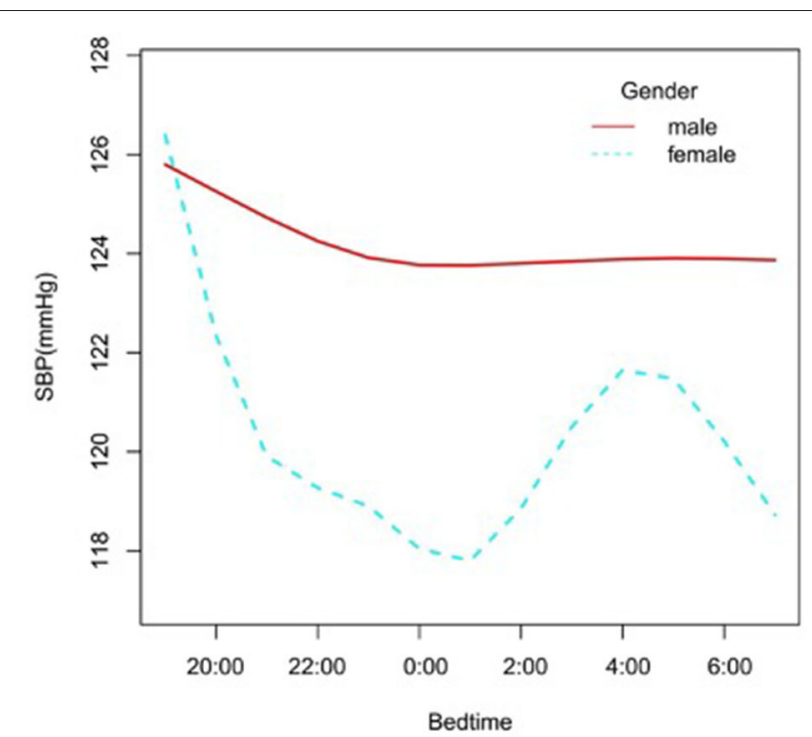

FIGURE 3 | A smooth curve fitting for the relationship between bedtime at night and SBP based on different gender. Adjust for age, race, alcohol consumption, smoke, TPA, GFR, UA, BMI, diabetes, HDL, LDL, TC, sleep duration, snore, trouble sleeping, snort or stop breathing, overly sleepy.

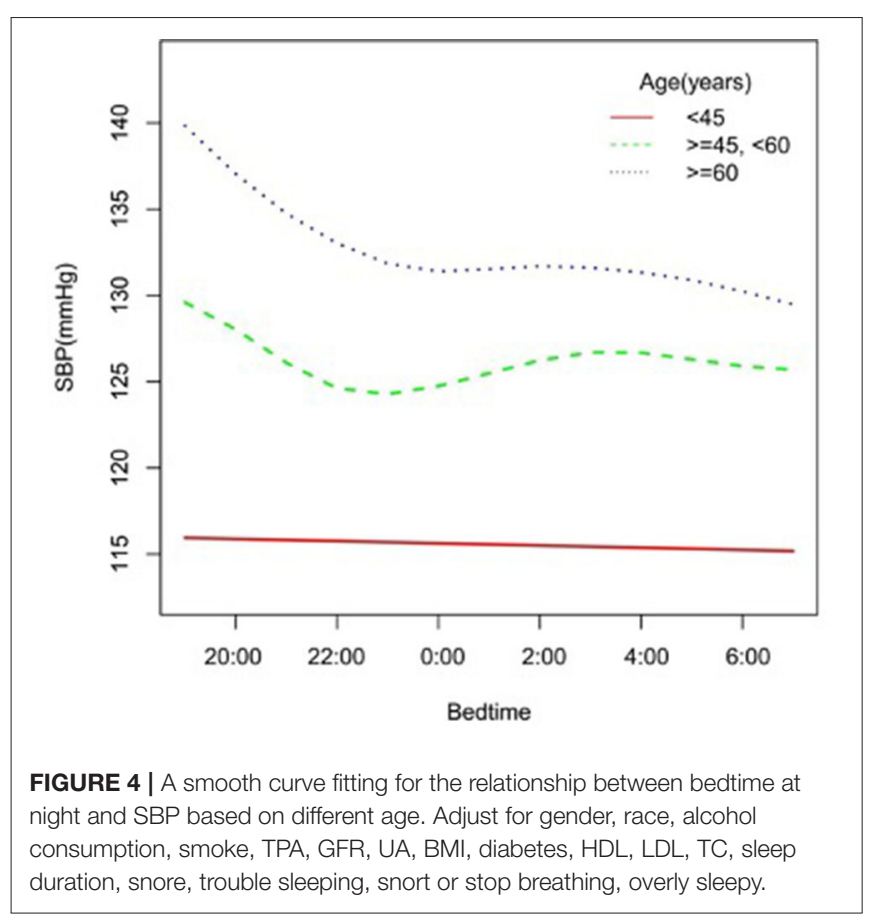

\section{DISCUSSION}

With the development of society and the economy, people's sleep patterns, including bedtime, wake time, and sleep duration, have been changed a lot. Sleep has been identified as a key lifestyle factor for cardiovascular disease (3). Many studies have explored the association between sleep duration and BP. A

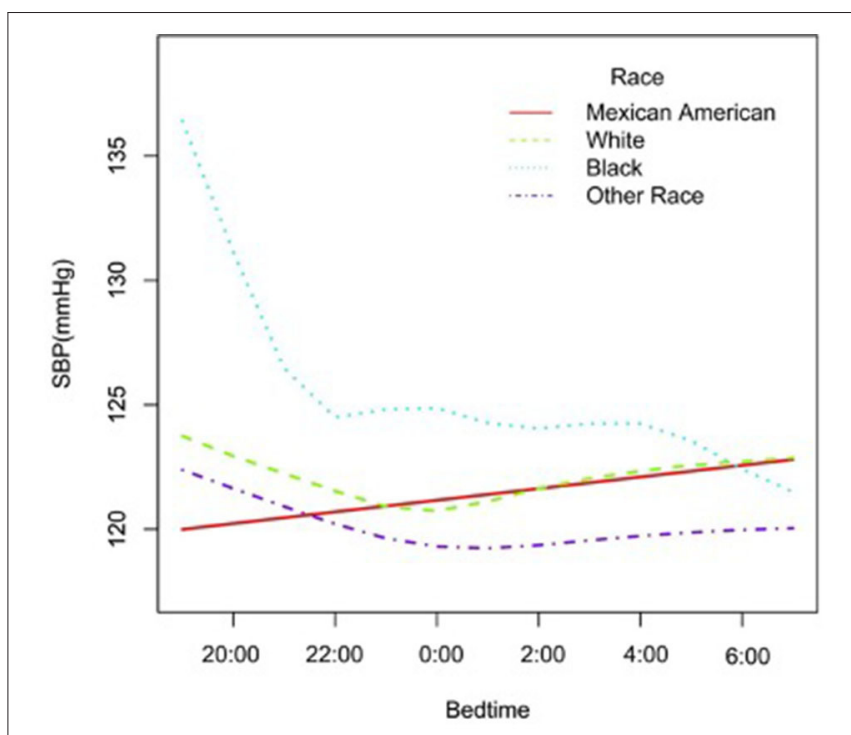

FIGURE 5 | A smooth curve fitting for the relationship between bedtime at night and SBP based on different race. Adjust for gender, age, alcohol consumption, smoke, TPA, GFR, UA, BMI, diabetes, HDL, LDL, TC, sleep duration, snore, trouble sleeping, snort or stop breathing, overly sleepy.

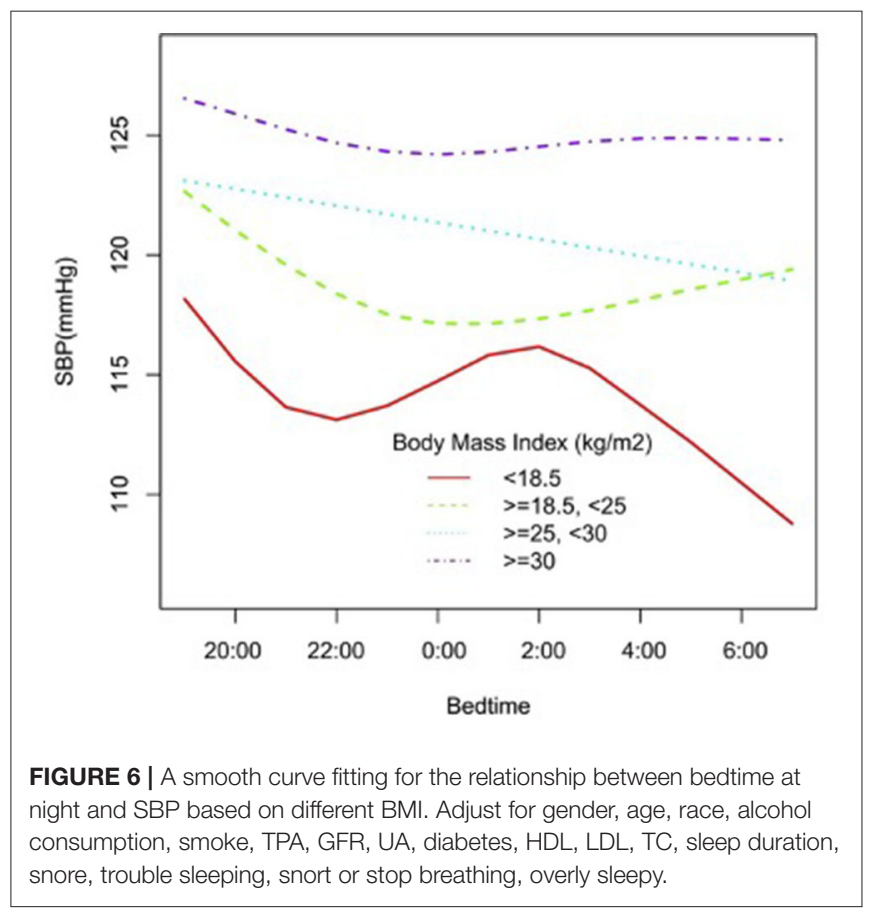

prospective cohort study, which included 162,121 adults, proved that self-reported short sleep duration $(<6 \mathrm{~h})$ increased the risk of hypertension $(\geq 130 / 85 \mathrm{mmHg})$ by $8 \%$ hazard ratio [HR] (95\% CI) 1.08 (1.04-1.13)\} (20). Another research with 71,455 participants demonstrated that compared with the $8 \mathrm{~h}$ group, people whose sleep duration was $<6 \mathrm{~h}$ or $6 \mathrm{~h}$ were more likely to develop hypertension (odds ratio (OR):1.49 (1.34-1.64) and 
1.15 (1.08-1.23), respectively) (8). As to long sleep duration, the association was not very clear. One study with 5,910 participants illuminated that compared to sleep duration with $7-8 \mathrm{~h}$, the adjusted ORs of $8-9$ and $\geq 9$ of sleep duration to hypertension was 1.19 (1.04-1.37) and 1.30 (1.04-1.62), respectively (21). However, 2 meta-analyses concluded that long sleep duration was not related to the occurrence of hypertension $(22,23)$. Earlier bedtime or later bedtime generally means longer or shorter sleep duration. In our study, a U-shaped relationship was identified between bedtime and SBP. A prospective cohort study identified that among adolescents, compared to participants with weekday bedtime between 9 p.m. and 10 p.m., participants with bedtime at 11 p.m. or later on weekdays had a 1.87 times higher risk of increased BP during the follow-up period $(95 \% \mathrm{CI}=1.09,2.21)$. A participant with earlier bedtime on a weekday also had a higher risk of elevated $\mathrm{BP}$ (risk ratio $=1.96 ; 95 \% \mathrm{CI}=1.27,3.01)(24)$, which was similar compared with our research.

The biological mechanism of the relationship between sleep patterns and BP has not been clear yet. Circadian rhythms including body temperature, sleep-wake cycle, metabolism, and $\mathrm{BP}$, were controlled by the central clock of the suprachiasmatic nucleus of the hypothalamus and the peripheral clocks throughout the body (25). BP was controlled by many different systems including the sympathetic nervous system, central nervous system, kidneys, heart, vascular system, and immune system, which ultimately lead to changes in cardiac output and peripheral resistance, thereby causing changes in BP (26). Different sleep duration or bedtime could disturb the circadian rhythm of BP, which would cause changes in autonomic nerve tension (7). Autonomic dysfunction, especially sympathetic activation, may lead to the occurrence and development of

hypertension and the reduction of nocturnal dipping $(27,28)$. In epidemiological studies, short sleep duration and long sleep duration were both associated with increased incidence of obesity and type 2 diabetes (3), which also played a role in promoting the occurrence and development of hypertension. Falling asleep too early or too late would disrupt the normal sleep-wake cycle. Previous studies clarified that when a sleep-wake cycle of an individual was inconsistent with the external environment, the

\section{REFERENCES}

1. Hunter DJ. Gene-environment interactions in human diseases. Nat Rev Genet. (2005) 6:287-98. doi: 10.1038/n rg1578

2. Yoon SS, Ostchega Y, Louis T. Recent Trends in the Prevalence of High Blood Pressure and its Treatment and Control, 19992008. NCHS Data Brief. (2010). p. 1-8. doi: 10.1037/e6656020 $10-001$

3. St-Onge MP, Grandner MA, Brown D, Conroy MB, Jean-Louis G, Coons M, et al. Sleep Duration and Quality: Impact on Lifestyle Behaviors and Cardiometabolic Health: A Scientific Statement From the American Heart Association. Circulation. (2016) 134:e367-86. doi: 10.1161/CIR.0000000000000444

4. Altevogt BM, Colten HR. (eds) Sleep Disorders and Sleep Deprivation: An Unmet Public Health Problem. Washington (DC). National Academies Press (US). (2006). average arterial pressure would increase by 3\% (29). Although the clinical effects of bedtime on BP may not be significant in all populations, these effects may be significant in some special populations. One meta-analysis evaluating the use of antihypertensive drugs to prevent cardiovascular disease showed that a decrease of $1 \mathrm{mmHg}$ in SBP and a decrease of $0.5 \mathrm{mmHg}$ in diastolic BP was associated with a $4 \%$ decrease in stroke and a $2 \%$ decrease in coronary heart disease events (30).

There were some limitations in our study. First, subjective bedtime may have measurement errors and recall biases, and the covariate self-reported sleep duration had only a moderate correlation with the objective sleep duration (31). Second, we did not consider other potential confounding factors, such as sleep quality, socio-economic status, and educational status. Further research studies need to be done to comprehensively explore the association of more factors with hypertension.

\section{CONCLUSIONS}

With the delay of bedtime, the SBP showed a gradual decrease trend, and it dropped to the lowest at 0:00. After 0:00, the SBP was gradually increased with the delay of sleep time. A U-shaped relationship was identified between bedtime and SBP. In the female group, the range of SBP was decreased more obviously before 0:00.

\section{DATA AVAILABILITY STATEMENT}

Publicly available datasets were analyzed in this study. This data can be found at: https://www.cdc.gov/nchs/nhanes/index.htm.

\section{AUTHOR CONTRIBUTIONS}

YS and ND: conception, design, collection, and assembly of data. ND: administrative support. CL, YL, and LH: provision of study materials or patients. YS and LH: data analysis and interpretation. All authors final approval of manuscript.
5. Williams GD, Dufour M, Bertolucci D. Drinking levels, knowledge, and associated characteristics, 1985 NHIS findings. Public Health Rep. (1986) 101:593-8.

6. Schoenborn CA, Adams PE. Health behaviors of adults: United States, 20052007. Vital Health Stat. (2010) 10:1-132.

7. Cappuccio FP, Stranges S, Kandala NB, Miller MA, Taggart FM, Kumari $\mathrm{M}$, et al. Gender-specific associations of short sleep duration with prevalent and incident hypertension: the Whitehall II Study. Hypertension. (2007) 50:693-700. doi: 10.1161/HYPERTENSIONAHA.107.095471

8. Fang J, Wheaton AG, Keenan NL, Greenlund KJ, Perry GS, Croft JB. Association of sleep duration and hypertension among US adults varies by age and sex. Am J Hypertens. (2012) 25:335-41. doi: 10.1038/ajh.2011.201

9. Kim J, Jo I. Age-dependent association between sleep duration and hypertension in the adult Korean population. Am J Hypertens. (2010) 23:1286-91. doi: 10.1038/ajh.2010.166

10. Fernandez-Mendoza J, Vgontzas AN, Liao D, Shaffer ML, Vela-Bueno $\mathrm{A}$, Basta $\mathrm{M}$, et al. Insomnia with objective short sleep duration and 
incident hypertension: the Penn State Cohort. Hypertension. (2012) 60:92935. doi: 10.1161/HYPERTENSIONAHA.112.193268

11. Faraut B, Touchette E, Gamble H, Royant-Parola S, Safar ME, Varsat $B$, et al. Short sleep duration and increased risk of hypertension: a primary care medicine investigation. J Hypertens. (2012) 30:135463. doi: 10.1097/HJH.0b013e32835465e5

12. Smolensky MH, Hermida RC, Castriotta RJ, Portaluppi F. Role of sleepwake cycle on blood pressure circadian rhythms and hypertension. Sleep Med. (2007) 8:668-80. doi: 10.1016/j.sleep.2006.11.011

13. Fagard RH. Dipping pattern of nocturnal blood pressure in patients with hypertension. Expert Rev Cardiovasc Ther. (2009) 7:599-605. doi: 10.1586/erc.09.35

14. Presta V, Figliuzzi I, D’Agostino M, Citoni B, Miceli F, Simonelli F, et al. Nocturnal blood pressure patterns and cardiovascular outcomes in patients with masked hypertension. J Clin Hypertens. (2018) 20:123846. doi: $10.1111 /$ jch. 13361

15. Piercy KL, Troiano RP, Ballard RM, Carlson SA, Fulton JE, Galuska DA, et al. The physical activity guidelines for Americans. JAMA. (2018) 320:20208. doi: 10.1001/jama.2018.14854

16. Kim D, Konyn P, Cholankeril G, Ahmed A. Physical activity is associated with nonalcoholic fatty liver disease and significant fibrosis measured by fibroscan. Clin Gastroenterol Hepatol. (2021) S1542-3565(21)00693-5. doi: 10.1016/j.cgh.2021.06.029. [Epub ahead of print].

17. Levey AS, Coresh J, Greene T, Marsh J, Stevens LA, Kusek JW, et al. Expressing the modification of diet in renal disease study equation for estimating glomerular filtration rate with standardized serum creatinine values. Clin Chem. (2007) 53:766-72. doi: 10.1373/clinchem.2006.077180

18. WHO consultation. Obesity: preventing and managing the global epidemic. World Health Organ Tech Rep Ser. (2000) 894:1-253.

19. Watson NF, Badr MS, Belenky G, Bliwise DL, Buxton OM, Buysse D, et al. Joint consensus statement of the American academy of sleep medicine and sleep research society on the recommended amount of sleep for a healthy adult: methodology and discussion. Sleep. (2015) 38:116183. doi: $10.5665 /$ sleep. 4886

20. Deng HB, Tam T, Zee BC, Chung RY, Su X, Jin L, et al. Short sleep duration increases metabolic impact in healthy adults: a population-based cohort study. Sleep. (2017). 40:zsx130. doi: 10.1093/sleep/zsx130

21. Gottlieb DJ, Redline S, Nieto FJ, Baldwin CM, Newman AB, Resnick HE, et al. Association of usual sleep duration with hypertension: the sleep heart health study. Sleep. (2006) 29:1009-14. doi: 10.1093/sleep/29.8.1009

22. Guo X, Zheng L, Wang J, Zhang X, Zhang X, Li J, et al. Epidemiological evidence for the link between sleep duration and high blood pressure: a systematic review and meta-analysis. Sleep Med. (2013) 14:324-32. doi: 10.1016/j.sleep.2012.12.001

23. Meng L, Zheng Y, Hui R. The relationship of sleep duration and insomnia to risk of hypertension incidence: a meta-analysis of prospective cohort studies. Hypertens Res. (2013) 36:985-95. doi: 10.1038/hr.2 013.70

24. Jansen EC, Dunietz GL, Matos-Moreno A, Solano M, Lazcano-Ponce E, Sánchez-Zamorano LM. Bedtimes and Blood Pressure: A Prospective Cohort Study of Mexican Adolescents. Am J Hypertens. (2020) 33:26977. doi: 10.1093/ajh/hpz191

25. Douma LG, Gumz ML. Circadian clock-mediated regulation of blood pressure. Free Radic Biol Med. (2018) 119:10814. doi: 10.1016/j.freeradbiomed.2017.11.024

26. Coffman TM. Under pressure: the search for the essential mechanisms of hypertension. Nat Med. (2011) 17:1402-9. doi: 10.1038/nm.2541

27. Sherwood A, Routledge FS, Wohlgemuth WK, Hinderliter AL, Kuhn $\mathrm{CM}$, Blumenthal JA. Blood pressure dipping: ethnicity, sleep quality, and sympathetic nervous system activity. Am J Hypertens. (2011) 24:9828. doi: 10.1038/ajh.2011.87

28. Mancia G, Grassi G. The autonomic nervous system and hypertension. Circ Res. (2014) 114:1804-14. doi: 10.1161/CIRCRESAHA.114.302524

29. Scheer FA, Hilton MF, Mantzoros CS, Shea SA. Adverse metabolic and cardiovascular consequences of circadian misalignment. Proc Natl Acad Sci U S A. (2009) 106:4453-8. doi: 10.1073/pnas.0808180106

30. Law MR, Morris JK, Wald NJ. Use of blood pressure lowering drugs in the prevention of cardiovascular disease: meta-analysis of 147 randomised trials in the context of expectations from prospective epidemiological studies. BMJ. (2009) 338:b1665. doi: 10.1136/bmj.b1665

31. Lauderdale DS, Knutson KL, Yan LL, Liu K, Rathouz PJ. Self-reported and measured sleep duration: how similar are they. Epidemiology. (2008) 19:83845. doi: 10.1097/EDE.0b013e318187a7b0

Conflict of Interest: The authors declare that the research was conducted in the absence of any commercial or financial relationships that could be construed as a potential conflict of interest.

Publisher's Note: All claims expressed in this article are solely those of the authors and do not necessarily represent those of their affiliated organizations, or those of the publisher, the editors and the reviewers. Any product that may be evaluated in this article, or claim that may be made by its manufacturer, is not guaranteed or endorsed by the publisher.

Copyright (c) 2021 Su, Li, Long, He and Ding. This is an open-access article distributed under the terms of the Creative Commons Attribution License (CC BY). The use, distribution or reproduction in other forums is permitted, provided the original author(s) and the copyright owner(s) are credited and that the original publication in this journal is cited, in accordance with accepted academic practice. No use, distribution or reproduction is permitted which does not comply with these terms. 